\title{
A Double Calibration Approach to the Estimation of Technological Change
}

\author{
Shinichiro OKUSHIMA ${ }^{a}$ and Makoto TAMURA ${ }^{b}$ \\ a Graduate School of Systems and Information Engineering, University of Tsukuba, \\ 1-1-1, Ten-nodai, Tsukuba-science-city, Ibaraki, 305-8573, Japan \\ b Institute for Global Change Adaptation Science, Ibaraki University, 2-1-1, \\ Bunkyo, Mito-city, Ibaraki, 310-8512, Japan
}

\begin{abstract}
This paper suggests a new methodology for evaluating technological change in a multi-sector general equilibrium framework. The double calibration technique was applied to an ex post decomposition analysis of technological change between two periods, enabling a distinction to be made between price-induced and factor-biased technological changes for each sector. The method is applied to an empirical casethe oil crises in Japan between 1970 and 1980.
\end{abstract}

JEL classification: D57, D58, O30

Keywords: Calibration, General equilibrium model, Technological change 


\section{Introduction}

Although several decades have passed since Solow’s seminal papers appeared, there is still room for progress in the estimation of technological change. Although the estimation is cumbersome, it is necessary if we want to understand the contribution of factors to economic growth or the change of economic structures over time.

The purpose of this paper is to suggest a new approach to the estimation of technological change. One of the most common methods is the Total Factor Productivity measurement or the Growth Accounting method shaped by Solow (1957), which decomposes output growth into measured increases in factor inputs and technical change (see, for example, Denison, 1967; Jorgenson and Griliches, 1967).

This method is of great significance with regards to the explicit integration of economic theory into such a decomposition (Griliches, 1996). This paper is motivated by Solow's theme. The "new wrinkle" we want to describe is an elementary way of segregating technological change due to price substitution effects from that due to other effects, capturing the interdependence among economic sectors. The double calibration technique (Dawkins et al., 2001) is applied to decompose technological change.

This method also takes over the inheritance of the Input Output (IO) analysis. In the IO framework, Structural Decomposition Analysis (SDA) has recently developed into a major tool for decomposition (Rose and Casler, 1996), as it overcomes the static features of the IO analysis and enables us to examine structural 
changes. However, as Rose and Casler (1996) points out, “a rigorous grounding in economic theory is lacking for SDA”. This paper may provide some additional theoretical underpinnings to IO analysis.

In addition, the method has an advantage in terms of data availability or efficiency. Although the attempt to conduct econometric studies often suffers from data insufficiency, our approach requires only two period datasets. It is therefore a practical alternative to econometrics.

Section 2 explains the methodology, while Section 3 applies this method to an empirical case, the oil crises in Japan. Our method can segregate price-induced technological change from other causes, and the analysis may have some implications for Japanese environmental policy, including the carbon tax that is currently being discussed. 


\section{The methodology}

In this section, our new method of evaluation is explained. The new feature of the method is the application of the double calibration technique to ex post decomposition analysis of technological change between two periods. ${ }^{1,2}$ This technique enables us to disentangle the individual causes from a series of simultaneous shocks to an economy in consistent with the general equilibrium theory. In the paper, total technological change (TTC) can be decomposed exactly into two components, price-induced technological change (PITC) and factor-biased technological change (FBTC).

Let us consider the behavior of industries. Their production functions are given by constant-returns-to-scale CES functions, and they are assumed to act so as to maximize their profits in competitive markets. Capital (K) and labor (L) are the

${ }^{1}$ For more information on the double calibration technique, see Dawkins et al. (2001). The double calibration technique has been attempted only a few times. Piggott and Whalley (2001) analyzes the effects of Canadian tax reform and Abrego and Whalley (2005) decomposes wage inequality change in UK using the double calibration technique. However, to the best of our knowledge, no studies have ever attempted to apply the double calibration technique to the decomposition of technological change as our paper does.

${ }^{2}$ In the analysis, like other literature on this subject, technological change is defined as changes of factor inputs per unit output, which is identical to the changes of input coefficients in IO tables. 
primary factors of production. Hence, factor inputs per unit output (hereafter factor inputs) in the initial period $(t=t-1)$ are derived as in equation (1):

$$
\frac{x_{i j}^{t-1}}{X_{j}^{t-1}}=\lambda_{i j}^{t-1} \beta_{j}^{\sigma_{j}-1}\left(\alpha_{i j} \frac{p_{j}^{t-1}}{p_{i}^{t-1}}\right)^{\sigma_{j}}, i=1, . ., n, \mathrm{~K}, \mathrm{~L} ; j=1, . ., n,
$$

where $x_{i j}^{t-1}$ is the input of $i$ by sector $j$ in $t-1, X_{j}^{t-1}$ is the output of sector $j$ in $t-1, p_{i}^{t-1}$ is the price of $i$ in $t-1, \sigma_{j}$ is the elasticity of substitution of sector $j, \lambda_{i j}^{t-1}$ is the FBTC parameter in $t-1, \alpha_{i j}$ is the share parameter $\left(\sum_{i} \alpha_{i j}=1\right)$, and $\beta_{j}$ is the scale parameter.

The parameter $\lambda_{i j}$ embodies (sector-specific) FBTC. $\lambda_{i j}^{t-1}$ is set at unity. This is normalization because only changes of $\lambda_{i j}$ are relevant in our study. $p_{i}^{t-1}$ is also one because it is from the actual price data which is normalized so that the prices in the initial period are one (See Section 3). When the values of $x_{i j}^{t-1}$ and $X_{j}^{t-1}$ are obtained from the dataset, and the substitution parameters $\sigma_{j}$ are exogenously given, all parameters of the production functions, $\alpha_{i j}$ and $\beta_{j}$, are determined to reproduce the actual economic structure in $t-1$ as an equilibrium. This is the same procedure followed under the conventional single calibration technique. ${ }^{3}$ Then, the production functions are specified. The parameters, $\alpha_{i j}, \beta_{j}$ and $\sigma_{j}$, are assumed to be invariant over the periods.

Next, in the terminal period $(t=t)$, factor inputs in $t$ are given by equation (2):

${ }^{3}$ For more information on the single calibration technique, see Dawkins et al. (2001), Mansur and Whalley (1984) and Shoven and Whalley (1992). 


$$
\frac{x_{i j}^{t}}{X_{j}^{t}}=\lambda_{i j}^{t} \beta_{j}^{\sigma_{j}-1}\left(\alpha_{i j} \frac{p_{j}^{t}}{p_{i}^{t}}\right)^{\sigma_{j}},
$$

where $x_{i j}^{t}$ is the input of $i$ by sector $j$ in $t, X_{j}^{t}$ is the output of sector $j$ in $t, p_{i}^{t}$ is the price of $i$ in $t$, and $\lambda_{i j}^{t}$ is the FBTC parameter in $t$.

In the double calibration technique, another data period is used to specify unknown parameters. Hence, when the values of $x_{i j}^{t}, X_{j}^{t}$ and $p_{i}^{t}$ are obtained from the dataset, the FBTC parameters $\lambda_{i j}^{t}$ are endogenously determined to replicate the economic structure in $t$ as another equilibrium. In other words, $\lambda_{i j}^{t}$ are chosen to fill the gap between the counterfactual point associated with the price change under the specified production functions and the actual equilibrium in $t$.

From equations (1) and (2), the changes in factor inputs are:

$$
\begin{aligned}
& \frac{\Delta\left(x_{i j} / X_{j}\right)}{\left(x_{i j} / X_{j}\right)}=\sigma_{j} \frac{\Delta\left(p_{j} / p_{i}\right)}{\left(p_{j} / p_{i}\right)}+\frac{\Delta \lambda_{i j}}{\lambda_{i j}}, \\
\Leftrightarrow & \text { TTC = PITC }+ \text { FBTC. }
\end{aligned}
$$

As in equation (3), changes in factor inputs (TTC) are decomposed into PITC and FBTC. PITC, which depends on the elasticity of substitution $\sigma_{j}$ and the change in relative prices over the periods, embodies the price substitution effects on the production functions. On the other hand, FBTC embodies the parts of the factor input change that cannot be explained by price substitution effects. Hence, when $\lambda_{i j}^{t}>1$, factor-augmenting technological change occurs, while when $\lambda_{i j}^{t}<1$, factor-diminishing technological change occurs. 
Figure 1 illustrates the concept of the method. From a theoretical viewpoint, PITC represents the change in factor inputs along the production functions, and FBTC represents the shift of the production functions. In contrast to IO analysis, in which technological change is measured without respect to price change, our new method can explicitly incorporate price substitution effects into the evaluation of technological change.

Further, equation (2) can also be expressed as equation (4) using matrices:

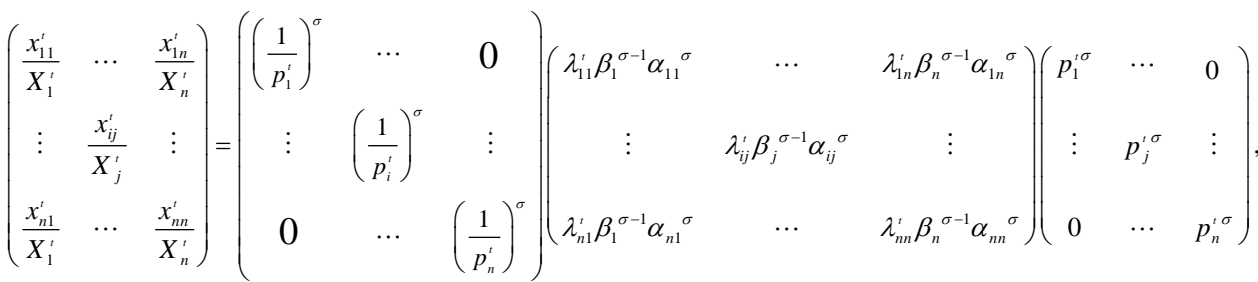

$$
\begin{aligned}
& \Leftrightarrow \mathbf{A}=\hat{\mathbf{Q}} \mathbf{L} \hat{\mathbf{P}} .
\end{aligned}
$$

Interestingly, equation (4) is similar to the RAS matrices in IO analysis (e.g., Bacharach, 1970). In the RAS terminology, $\hat{\mathbf{Q}}$ is regarded as the $\hat{\mathbf{R}}$ matrix, which represents substitution effects, and $\hat{\mathbf{P}}$ is regarded as the $\hat{\mathbf{S}}$ matrix, which represents fabrication effects.

\section{[Insert Figure 1 here]}




\section{Empirical results}

In this section, this evaluation method is applied to an actual case, the oil crises in Japan. In the 1970s, skyrocketing oil prices greatly influenced the Japanese economy. This situation offers a typical example to apply our method.

For the analysis, 1970 and 1980 data are used. Nominal outputs (factor inputs) are obtained from Input-Output Tables (Management and Coordination Agency). Prices of goods and services are from the Domestic Wholesale Price Index (Bank of Japan) ${ }^{4}$ or Deflators on Outputs of National Accounts (Economic Planning Agency). ${ }^{5}$ Capital and labor prices are estimated following Ito and Murota (1984). These prices are normalized so that the prices in the initial period are one. Then, in our study, units of goods, services and factors are defined as those which cost one Japanese-yen in 1970. This is the units convention, originally adopted by Harberger (1962), and widely used since (Dawkins et al., 2001; Shoven and Whalley, 1992). The convention enables us to obtain consistent units across time. Hence, real outputs (factor inputs) are obtained by deflating nominal outputs by the prices.

Tables 1-3 show FBTC in the cases where $\sigma=0, \sigma=0.5$ and $\sigma=1$, respectively. ${ }^{6}$ FBTC, which is represented as a percentage change, varies depending on

${ }^{4}$ For EII, MAC, OMF, COAL, OIL, ELC and GAS.

5 For AGM and SER.

${ }^{6}$ In this paper, elasticities of substitution are assumed to be constant in all sectors and between inputs for simplicity. However, this methodology can be applied to the case 
$\sigma$. First, in the case where $\sigma=0$, there is no price substitution and PITC $=0$. Hence, FBTC explains all the changes in factor inputs, i.e., FBTC can be regarded as technological change itself. Next, as shown in the Tables, FBTC changes in line with changes in $\sigma$. A larger $\sigma$ makes price substitution effects more likely. Therefore, the more $\sigma$ increases, the larger the proportion of TTC that is explained by PITC. In the analysis, elasticities of substitution are arbitrarily changed between zero and one, since the purpose here is to explain our methodology. In practice, empirically estimated parameters should be used for substitution parameters. For the Japanese case, the existing literature (e.g., Tokutsu, 1994) shows that most elasticities of substitution are below one.

Here, the case of OIL is analyzed as an example, since FBTC for OIL is considered to be greatly affected by the oil crises. In the case where $\sigma=0$ (no price substitution) in Table 1, most sectors have a negative FBTC for OIL. This means that factor inputs of OIL decreased in most sectors, implying that OIL-saving technological change occurred in the 1970s.

However, price substitution effects had occurred in reality. These effects are taken into consideration in Tables 2 and 3. As has been seen, FBTC for OIL increases as $\sigma$ becomes larger. In Table 3, all the sectors have a positive FBTC for OIL, which means factor-augmenting technological change occurred. This implies that price

where elasticities are different in each sector and between inputs using nested production functions. 
substitution effects were expected to induce a larger decrease in factor inputs of OIL, whereas factor inputs did not decrease to the degree that was expected from these effects. In sum, OIL-saving technological change over the periods can be explained entirely by PITC, rather than FBTC.

[Insert Table 1, 2 and 3 here] 


\section{Conclusion}

This paper proposed a new methodology for the evaluation of technological change. This method serves as an elementary but powerful tool for empirical studies. In addition, it may give some micro-theoretical foundations to conventional methods. Griliches (1996) has mentioned that all the pioneers of this subject were clear about the tenuousness of the estimation of technological change. This caution holds true for our method as well - for example, one limitation of the method is that it employs a deterministic procedure. The method could be more fruitful if used complementarily with other conventional methods such as IO-SDA or econometric methods.

\section{Acknowledgements}

This research was supported by the Grant-in-Aid for Scientific Research. The name order is alphabetical. 


\section{References}

Abrego, L. \& Whalley, J. (2005). Decompositional analysis using numerical equilibrium models: Illustrations from trade literature. In T. J. Kehoe, T.N. Srinivasan \& J. Whalley (Eds.), Frontiers in Applied General Equilibrium Modeling (pp.378-401). Cambridge: Cambridge University Press.

Bacharach, M. (1970). Biproportional matrices \& input-output change. Cambridge: Cambridge University Press.

Dawkins, C., Srinivasan, T. N., \& Whalley, J. (2001). Calibration. In J. J. Heckman \& E. Leamer (Eds.), Handbook of econometrics, vol.5 (pp.3653-3703). New York: Elsevier Science.

Denison, E. F. (1967). Why growth rates differ. Washington, DC: The Brookings Institution.

Griliches, Z. (1996). The discovery of the residual: A historical note. Journal of Economic Literature, 34(3), 1324-1330.

Harberger, A. C. (1962). The incidence of the corporation income tax. Journal of Political Economy, 70(3), 215-240.

Ito, K. \& Murota, Y. (1984). A macro economic modeling by using translog cost function. Journal of Japan Economic Research, 13, 31-41 (in Japanese).

Jorgenson, D. W. \& Griliches, Z. (1967). The explanation of productivity change. Review of Economic Studies, 34(3), 249-283. 
Mansur, A. \& Whalley, J. (1984). Numerical specification of applied general equilibrium models: Estimation, calibration, and data. In H. E. Scarf \& J. B. Shoven (Eds.), Applied general equilibrium analysis (pp.69-127). Cambridge: Cambridge University Press.

Piggott, J. \& Whalley, J. (2001). VAT base broadening, self supply, and the informal sector. American Economic Review, 91(4), 1084-1094.

Rose, A. \& Casler, S. (1996). Input-output structural decomposition analysis: A critical appraisal. Economic Systems Research, 8(1), 33-62.

Shoven, J. B. \& Whalley, J. (1992). Applying general equilibrium. Cambridge: Cambridge University Press.

Solow, R. M. (1957). Technical change and the aggregate production function. Review of Economics and Statistics, 39(3), 312-320.

Tokutsu, I. (1994). Econometric analysis of production structure. Tokyo: Sobunsha Publishing Co.(in Japanese). 
Table 1 Factor-biased technological change (percentage changes) when $\sigma=0$

\begin{tabular}{|c|c|c|c|c|c|}
\hline \multirow[t]{2}{*}{ Input $^{\mathrm{a}}$} & \multicolumn{5}{|l|}{ Sector } \\
\hline & AGM & EII & MAC & OMF & SER \\
\hline$\overline{\mathrm{AGM}}$ & $-4.7 \%$ & $-32.4 \%$ & $-53.1 \%$ & $-0.4 \%$ & $-1.8 \%$ \\
\hline EII & $15.4 \%$ & $-3.1 \%$ & $-69.3 \%$ & $18.1 \%$ & $2.1 \%$ \\
\hline MAC & $105.5 \%$ & $23.0 \%$ & $4.9 \%$ & $109.0 \%$ & $36.0 \%$ \\
\hline OMF & $0.1 \%$ & $-5.7 \%$ & $-58.7 \%$ & $-11.1 \%$ & $-32.4 \%$ \\
\hline SER & $32.4 \%$ & $-2.0 \%$ & $-36.9 \%$ & $29.1 \%$ & $5.3 \%$ \\
\hline COAL & $-117.3 \%$ & $-12.2 \%$ & $-142.1 \%$ & $-72.5 \%$ & $-5.7 \%$ \\
\hline OIL & $-11.2 \%$ & $-8.0 \%$ & $-117.3 \%$ & $0.6 \%$ & $-51.2 \%$ \\
\hline ELC & $28.2 \%$ & $2.6 \%$ & $-37.6 \%$ & $36.5 \%$ & $20.4 \%$ \\
\hline GAS & $40.0 \%$ & $32.0 \%$ & $-59.4 \%$ & $34.0 \%$ & $54.3 \%$ \\
\hline K & $29.3 \%$ & $11.2 \%$ & $-33.0 \%$ & $52.9 \%$ & $37.0 \%$ \\
\hline $\mathrm{L}$ & $-57.8 \%$ & $-31.6 \%$ & $-85.1 \%$ & $-19.1 \%$ & $-25.9 \%$ \\
\hline
\end{tabular}

${ }^{\text {a }}$ Classifications are as follows.

AGM: Agriculture, forestry, fishery and mining, EII: Energy intensive industry (paper and pulp, chemical, ceramics, and iron and steel), MAC: Machinery, OMF: Other manufacturing, SER: Services and others, COAL: Coal and coal products, OIL: Oil and oil products, ELC: Electricity, GAS: Gas, K: Capital, L: Labor. 
Table 2 Factor-biased technological change (percentage changes) when $\sigma=0.5$

\begin{tabular}{|c|c|c|c|c|c|}
\hline \multirow[t]{2}{*}{ Input $^{\mathrm{a}}$} & \multicolumn{5}{|l|}{ Sector } \\
\hline & AGM & EII & MAC & OMF & SER \\
\hline$\overline{\mathrm{AGM}}$ & $-4.7 \%$ & $-32.0 \%$ & $-29.6 \%$ & $-8.7 \%$ & $-5.2 \%$ \\
\hline EII & $15.1 \%$ & $-3.1 \%$ & $-46.2 \%$ & $9.4 \%$ & $-1.7 \%$ \\
\hline MAC & $82.0 \%$ & $-0.1 \%$ & $4.9 \%$ & $77.1 \%$ & $9.1 \%$ \\
\hline OMF & $8.5 \%$ & $3.0 \%$ & $-26.8 \%$ & $-11.1 \%$ & $-27.5 \%$ \\
\hline SER & $35.9 \%$ & $1.8 \%$ & $-9.9 \%$ & $24.1 \%$ & $5.3 \%$ \\
\hline COAL & $-103.2 \%$ & $2.2 \%$ & $-104.5 \%$ & $-66.8 \%$ & $5.0 \%$ \\
\hline OIL & $36.8 \%$ & $40.4 \%$ & $-45.7 \%$ & $40.2 \%$ & $-6.6 \%$ \\
\hline ELC & $51.5 \%$ & $26.3 \%$ & $9.2 \%$ & $51.5 \%$ & $40.3 \%$ \\
\hline GAS & $53.8 \%$ & $46.2 \%$ & $-22.2 \%$ & $39.4 \%$ & $64.6 \%$ \\
\hline K & $4.7 \%$ & $-13.0 \%$ & $-34.0 \%$ & $20.0 \%$ & $9.0 \%$ \\
\hline $\mathrm{L}$ & $-32.2 \%$ & $-5.5 \%$ & $-35.9 \%$ & $-1.8 \%$ & $-3.7 \%$ \\
\hline
\end{tabular}

${ }^{\text {a }}$ Classifications are the same as in Table 1. 
Table 3 Factor-biased technological change (percentage changes) when $\sigma=1$

\begin{tabular}{|c|c|c|c|c|c|}
\hline \multirow[t]{2}{*}{ Input $^{\mathrm{a}}$} & \multicolumn{5}{|l|}{ Sector } \\
\hline & AGM & EII & MAC & OMF & SER \\
\hline AGM & $-4.7 \%$ & $-31.7 \%$ & $-6.1 \%$ & $-17.1 \%$ & $-8.7 \%$ \\
\hline EII & $14.7 \%$ & $-3.1 \%$ & $-23.0 \%$ & $0.7 \%$ & $-5.5 \%$ \\
\hline MAC & $58.5 \%$ & $-23.3 \%$ & $4.9 \%$ & $45.2 \%$ & $-17.9 \%$ \\
\hline OMF & $16.8 \%$ & $11.8 \%$ & $5.0 \%$ & $-11.1 \%$ & $-22.6 \%$ \\
\hline SER & $39.3 \%$ & $5.6 \%$ & $17.0 \%$ & $19.2 \%$ & $5.3 \%$ \\
\hline COAL & $-89.1 \%$ & $16.7 \%$ & $-66.9 \%$ & $-61.1 \%$ & $15.6 \%$ \\
\hline OIL & $84.9 \%$ & $88.7 \%$ & $25.8 \%$ & $79.9 \%$ & $38.0 \%$ \\
\hline ELC & $74.9 \%$ & $50.0 \%$ & $56.0 \%$ & $66.5 \%$ & $60.2 \%$ \\
\hline GAS & $67.6 \%$ & $60.3 \%$ & $15.1 \%$ & $44.9 \%$ & $75.0 \%$ \\
\hline $\mathrm{K}$ & $-19.8 \%$ & $-37.2 \%$ & $-35.1 \%$ & $-12.9 \%$ & $-19.0 \%$ \\
\hline $\mathrm{L}$ & $-6.5 \%$ & $20.5 \%$ & $13.3 \%$ & $15.5 \%$ & $18.5 \%$ \\
\hline
\end{tabular}

${ }^{\text {a }}$ Classifications are the same as in Table 1. 


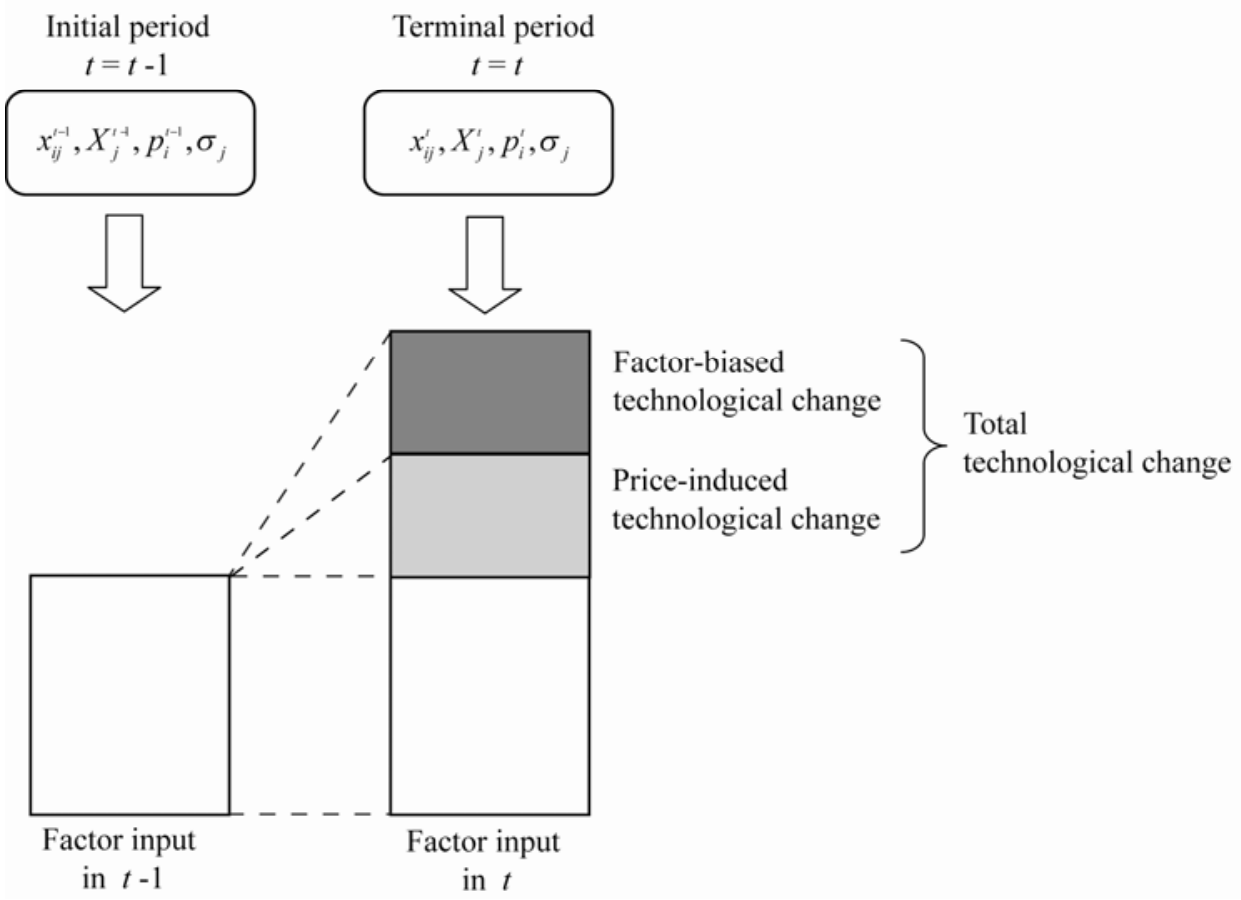

Figure 1 The method 